autograft rather than other valve prostheses in children, some specific reasons were present in this special situation. Resection of the aneurysmal aortic root was necessary and the relatively difficult access to the aortic root made the choice of a homograft less preferable in view of the inevitable reoperation.

The operation turned out to be straightforward. The anterior placement of the pulmonary trunk made its harvesting easy. Coronary artery problems were not encountered. Transposition may, however, be combined with coronary artery patterns that make harvesting of the pulmonary trunk more difficult, especially a right coronary artery crossing the right ventricular outflow tract. No important mismatch between the diameters of the pulmonary trunk and aortic anulus existed, which further encouraged us to choose the pulmonary autograft for aortic root replacement.

In conclusion, the Ross procedure is technically feasible after an arterial switch operation and may be a particularly attractive alternative for this special population. This may be even more true because it is the original aortic valve that is used to replace the insufficient neoaortic valve.

\section{REFERENCES}

1. Gittenberger-de Groot AC, Sauer U, Oppenheimer-Dekker A, Quaegebeur JM. Coronary arterial anatomy in transposition of the great arteries: a morphological study. Pediatr Cardiol 1983;4(suppl 1):15-24.

2. Klautz RIM, Ottenkamp J, Quaegebeur JM, Buis-Liem TN, Rohmer J. Anatomic correction for transposition of the great arteries: first follow-up (38 patients). Pediatr Cardiol 1989;10: $1-9$.

3. Yamaguchi M, Hosokawa Y, Imai Y, Kurosawa H, Yasui H, Yagihari T, et al. Early and midterm results of the arterial switch operation for transposition of the great arteries in Japan. J Thorac Cardiovase Surg 1990;100:261-9.

4. Ungerleider RM, Gaynor JW, Israel P, Kanter RJ, Armstrong BE. Report of neoaortic valve replacement in a ten-year-old girl after an arterial switch procedure for transposition. $J$ Thorac Cardiovasc Surg 1992;104:213-5.

5. Serraf A, Roux D, Lacour-Gayet F, Touchot A, Bruniaux J, Sousa-Uva M, et al. Reoperation after arterial switch operation for transposition of the great arteries. J Thorac Cardiovasc Surg 1995;110:892-9.

\title{
REVERSE FLAP OF DISTAL LATISSIMUS DORSI FOR DIAPHRAGM RECONSTRUCTION IN THE ADULT: SPECIFICATION OF THE TECHNICAL PROCEDURE AND REPORT ON SIX CASES
}

\author{
Amedeo V. Bedini, MD, Maurizio Valente, MD, Stefano Andreani, MD, and Gianni Ravasi, MD,* Milan, Italy
}

The current repair procedures of diaphragmatic defects in the adult, although uncommon, involve the routine use of prosthetic materials, ${ }^{1}$ whereas the use of autologous tissues and muscular flaps is preferred in pediatric subjects. $^{2}$ The recent clarification that the paraspinous dorsal perforating branches of the lower intercostal arteries and the lumbar vessels are reliable pedicles for the use of the whole latissimus dorsi (LD) muscle as a reverse flap ${ }^{3}$ prompted the use of this muscle in two experiences totaling eight children. Bianchi, Doig, and Cohen ${ }^{4}$ first used this flap for diaphragmatic hernia repair. More recently, Wallace and Roden $^{2}$ treated the congenital absence of the diaphragm by means of the reverse flap of the whole LD muscle and a Dexon patch (Davis \& Geck,

From the Thoracic Surgery Department, National Cancer Institute, Milan, Italy,

Received for publication March 10, 1997; accepted for publication March 17, 1997.

Address for reprints: Amedeo V. Bedini, Chirurgia Toracica, Istituto Nazionale Tumori, Via G. Venezian 1, 20133 Milan, Italy.

"Present address: Istituto Clinico Humanitas, Via Manzoni 56, 20089 Rozzano (MI), Italy.

J Thorac Cardiovasc Surg 1997;114:846-8

Copyright (C) 1997 by Mosby-Year Book, Inc.

$0022-5223 / 97 \$ 5.00+0 \quad \mathbf{1 2 / 5 4 / 8 1 9 4 5}$
Danbury, Conn.). We did not find any other publication on this topic in the literature. We describe the reconstruction of one hemidiaphragm in the adult by means of only the distal portion of the LD muscle, fashioned as a reverse flap.

The surgical procedure consists of an incision as for a posterolateral thoracotomy. The LD muscle is divided from the medial to the lateral margin at the projection points of the sixth and fifth ribs, respectively (Fig. 1), and its distal portion is then mobilized via extrafascial planes, down to just below the tenth rib. The serratus anterior muscle is mobilized as well to allow the primary thoracotomy, which is performed via the sixth or seventh intercostal space, or after subperiosteal resection of the sixth rib in case of an extrapleural pneumonectomy, without division of this muscle. The diaphragm is resected by means of an additional thoracotomy through the ninth or tenth intercostal space. The posterior tract of the rib overlying this second access is then resected over a distance of approximately $10 \mathrm{~cm}$, starting from the margin of the spinalis muscle. The distal portion of the LD muscle is threaded through this orifice into the chest, and its apex is fixed to the most distant point of the diaphragmatic defect (Fig. 2). One to-and-fro continuous Maxon 1-0 mattress suture (Davis \& Geck) is then applied to the medial margin of the defect, consisting of the lower pericardium or the remnant diaphragm, and the corresponding margin of the flap. A second similar suture is applied to 


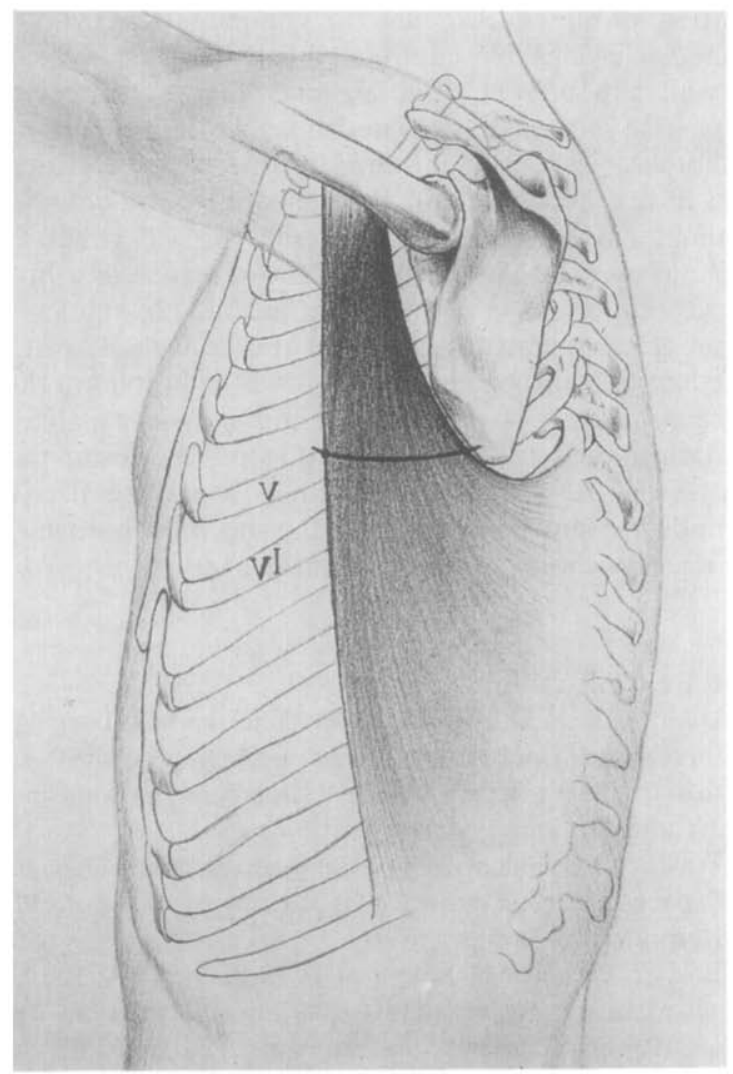

Fig. 1. The line of division of the LD muscle.

the lateral margin of the muscle flap and the chest wall, with fixation around the ribs overlying the access to the pleural cavity. Both these sutures are extended to the point of entry of the flap into the chest. The fascial and superficial portions of the flap facing the pleural cavity are then sewn to the overlying tissue consisting of the periosteum of the resected rib and the intercostal muscle, with a tight continuous Maxon 2-0 mattress suture, to construct a new costophrenic sinus. Finally, the thoracotomies are closed and the distal margin of the proximal portion of the LD muscle is sutured to the posterior margin of the serratus anterior muscle. Both these muscles are sutured to the rib plane with a continuous Maxon 1-0 mattress suture, according to their original anatomic positions. A very limited detachment of the tendon of the serratus anterior muscle from the scapula tip may occasionally be needed.

Three men and three women with a mean age of 40 years (range 22 to 64 years) underwent total $(n=3)$ or subtotal $(n=3)$ diaphragmatic resections at our department between April and September 1995. An extrapleural pneumonectomy was performed in four patients, a lower lobectomy in one, and an atypical sublobar resection in one. Three patients underwent a chest wall resection. Two patients had pleural mesothelioma, one had Ewing's sarcoma, two had pulmonary metastases (from chondrosarcoma and rhabdomyosarcoma), and one had recurrent hemangiopericytoma of the diaphragm. The left side was involved in three

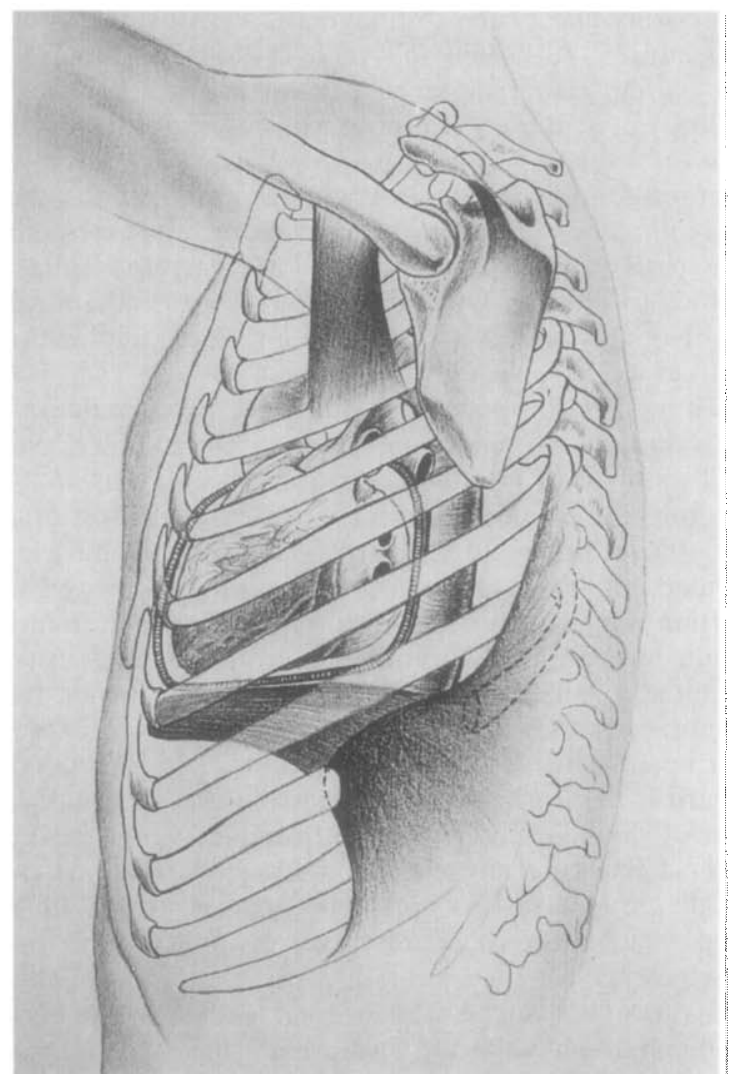

Fig. 2. After the extended resection of the diaphragm, the reverse flap of the distal LD muscle is threaded into the chest through the orifice obtained by resection of the posterior tract of the ninth or tenth rib and is sutured to the margins of the defect.

patients. One patient had had radiotherapy before the operation, two chemotherapy, and two both radiotherapy and chemotherapy. The mean dose of preoperative radiotherapy was 36 Gy (range 30 to 41 Gy). No operative deaths occurred. Postoperative complications included one case of "slow recovery," although without any objective impairment, and one case of atrial fibrillation. Two transcutaneous blood aspirations from the upper peritoneal cavity were required in one patient, who had had intraoperative spleen damage, because of malfunctioning of the abdominal drain. The mean duration of postoperative hospitalization was 22 days (range 8 to 37 days). The two patients in whom no pneumonectomy was performed underwent a reliable postoperative fluoroscopic examination, showing a stable neodiaphragm. However, paradoxic respiratory motion was clinically diagnosed or suspected in none of the patients. Adjuvant radiotherapy to the "diaphragmatic" region (mean dose $43 \mathrm{~Gy}$, range 24 to $55 \mathrm{~Gy}$ ) was delivered in three patients, one of whom had also received preoperative radiotherapy. One patient was given postoperative chemotherapy. One patient had a bronchopleural fistula without empyema 2 months after a right extrapleural pneumonectomy and was treated by 
temporary chest tube drainage and various endoscopic procedures. Although full recovery was not obtained, the patient remained free of infection until the end of follow-up, at the eighth month of observation. Six to 9 months after the operation, a physiatric evaluation was performed in five patients: no impairment in extending, adducting, or medially rotating the arm was assessed in any patient. All patients were alive at the time of follow-up closure (April 30, 1996), two of them with recurrent disease. None had had any late complications related to the operation.

The standard approach to perform lower pulmonary lobectomies or demolitions of the posterolateral chest wall, both involving diaphragmatic resection, as well as extrapleural pneumonectomies, consists of a posterolateral thoracotomy. In this procedure the LD muscle is divided entirely, and the contractile function of its distal portion is irreversibly lost. A posterior parallel counterincision in the ninth or tenth intercostal space is usually required for diaphragmatic resection. These two destructive procedures, which are needed only for surgical access, can be transformed into two reconstructive steps. With regard to the former, the functionally useless distal portion of the LD muscle can be fashioned into a reliable reverse flap to restore the nonfunctional anatomy of a neodiaphragm, just as prosthetic materials do. With regard to the latter, the second thoracotomy could be used as a passage for the elevation of the flap into the chest. This procedure can be used for total reconstruction of one hemidiaphragm, allowing a watertight separation between the pleural and peritoneal cavities and a stable mediastinum. In our opinion, the adaptability of the muscle makes the reconstructive procedure easier and more satisfactory than when prosthetic materials are used. Arm motion was not compromised in any function: this result could be due both to the firm anchorage of the still-functional proximal portion of the muscle and to compensation by other muscular groups. No flap-related complications were observed, although in three patients the procedure was applied in previously irradiated areas. Moreover, adjuvant radiotherapy was administered in one of these patients and in another two (without preoperative radiotherapy) without any adverse effects on the surgical result. No infections occurred, not even in the presence of a bronchopleural fistula, confirming the reliability of autologous tissues. Restriction to the use of the LD muscle can be needed only in patients who have had poliomyelitis, because it may be the only lateral muscle capable of elevating the pelvis for a forward step. ${ }^{5}$ We recommend the distal LD muscle fashioned as a reverse flap for hemidiaphragm replacement, believing this approach to be the first choice of treatment in the future.

\section{REFERENCES}

1. Harlow CL, Newell JD, Cink TM, Johnston MR. Imaging of the expanded polytetrafluoroethylene prosthetic diaphragm following extrapleural pneumonectomy for mesothelioma. J Thorac Imaging 1991;6:81-4.

2. Wallace CA, Roden JS. Reverse, innervated latissimus dorsi flap reconstruction of congenital diaphragmatic absence. Plast Reconstr Surg 1995;96:761-9.

3. Bostwick J, Scheflan M, Nahai F, Jurkiewicz MJ. The "reverse" latissimus dorsi muscle and musculocutaneous flaps: anatomical and clinical considerations. Plast Reconstr Surg 1980;65:395-9.

4. Bianchi A, Doig CM, Cohen SJ. The reverse latissimus dorsi flap for congenital diaphragmatic hernia repair. J Pediatr Surg 1983;18:560-3

5. Bostwick J, Nahai F, Wallace JG, Vasconez LO. Sixty latissimus dorsi flaps. Plast Reconstr Surg 1979;63:31-41.

\title{
DOUBLE SWITCH OPERATION FOR CORRECTED TRANSPOSITION WITH TOTAL ANOMALOUS PULMONARY VENOUS RETURN
}

\author{
Masaaki Yamagishi, MD, Yuzuru Nakamura, MD, Toshiyuki Kanazawa, MD, and Noriyasu Kawada, MD, \\ Saitama, Japan
}

From the Division of Cardiovascular Surgery, Saitama Children's Medical Center, Saitama, Japan.

Received for publication Jan. 30, 1997; accepted for publication March 7, 1997.

Address for reprints: Masaaki Yamagishi, MD, Department of Surgery II, Children's Research Hospital, Kyoto Prefectural University of Medicine, Kawaramachi, Hirokoji, Kamikyo-ku, Kyoto 602, Japan.

J Thorac Cardiovase Surg 1997;114:848-50

Copyright (C 1997 by Mosby-Year Book, Inc.

$0022-5223 / 97 \$ 5.00+0 \quad \mathbf{1 2 / 5 4 / 8 1 7 6 8}$
Anatomic correction of congenitally corrected transposition of the great arteries (TGA), the double switch operation, has been applied in children with associated cardiac anomalies and risk factors for systemic right ventricular function. ${ }^{1-3}$ The association of total anomalous pulmonary venous return (TAPVR) with congenitally corrected TGA, which is rare in the nonisomerism heart, may increase the difficulty of constructing competent intraatrial venous channels during the double switch operation. Only one case of congenitally corrected TGA in which all pulmonary veins returned to the coronary sinus has been reported previously. ${ }^{4} \mathrm{Here}$, we describe an infant with situs solitus, congenitally corrected TGA, and TAPVR who underwent a double switch operation con- 